\title{
Educação ambiental efetiva: a relação do homem com a natureza e a necessária mudança de atitudes e de valores éticos e morais
}

\author{
Vinicius Diniz e Almeida Ramos \\ Márcio Oliveira Portella
}

Educação ambiental efetiva: a relação do homem com a natureza e a necessária mudança de atitudes e de valores éticos e morais

Resumo: $O$ artigo tem como tema a educação ambiental e seu papel fundamental na preservação do meio ambiente, à luz do que prescreve a legislação brasileira. Procurou-se realizar um estudo a respeito do comportamento humano para, em seguida, abordar a necessária transformação de paradigmas, de modo que a educação ambiental amplie seu escopo, fazendo do processo educacional efetivo instrumento de proteção dos recursos naturais. Para tanto, utilizou-se a pesquisa bibliográfica, especialmente relacionada à legislação brasileira e às teorias e conceitos filosóficos acerca da relação do homem com a natureza. Como resultado da pesquisa, constatou-se que a abordagem da educação ambiental deve ser ampliada, de modo a estimular não somente ações pontuais, mas consistentes mudanças de atitudes e de comportamentos, estimulando a conscientização da sociedade sobre a importância da preservação do meio ambiente como condição para a sobrevivência da espécie humana.

Palavras-Chave: Educação ambiental. Atitudes. Comportamentos

Effective Environmental Education: man's relationship with nature and the necessary change in attitudes and ethical and moral values.

Abstract: The article focuses on environmental education and its fundamental role in preserving the environment in the light under the requirements of Brazilian law. Sought to carry out a study about human behavior to then address the necessary transformation of paradigms, so that environmental education broadens its scope, making effective educational process instrument of protection of natural resources. For this, was used the literature, especially related to Brazilian law and the theories and philosophical concepts about man's relationship with nature. As a result of the research, it was noted that the approach to environmental education should be expanded in order to stimulate not only specific actions but consistent changes in attitudes and behaviors by stimulating the awareness of society about the importance of preserving the environment as condition for the survival of the human species.

Key-Words: Environmental education. Attitudes. Behavior. 


\section{Introdução}

Desde a antiguidade, a filosofia procura compreender e interpretar a relação do homem com a natureza. A teoria socrática, por exemplo, introduz a ideia da moral, sobre a qual se edificam a ética e o direito. Na contemporaneidade, a moralidade é vista como a capacidade, própria do homem, em controlar seus impulsos e desejos: o homem racional molda seus desejos à razão.

É preciso repensar a educação ambiental como meio de promover uma nova relação do ser humano com a natureza, a partir das mudanças de atitudes e dos valores éticos e morais, concebendo-se o meio ambiente como parte integrante de um escopo maior capaz de desencadear novos comportamentos, mais alinhados à preservação ambiental e à sobrevivência da própria espécie humana.

A partir de uma análise pautada na legislação brasileira, o presente artigo objetiva investigar as nuances que permeiam a educação ambiental, partindo da premissa de que o processo educacional é complexo e exige uma visão sistêmica da sociedade, de modo que a preservação ambiental seja vista como um instrumento que integra um rol de elementos sociais, dentre os quais encontram-se a cultura, a política e a economia.

Para o alcance desse objetivo, buscar-se-á, inicialmente, promover incursões pela filosofia, especialmente para abordar teorias que procuraram compreender o homem em face da natureza, bem como interpretar as ações humanas sob o ponto de vista da ética e da moral.

O principal ponto de investigação será a pertinência e adequação do processo de educação ambiental atual, face à dinâmica da vida em sociedade, eis que não se admite, a priori, que o meio ambiente seja estudado - e soluções para seus problemas sejam buscadas - a partir de uma visão individualizada, que não contemple os aspectos ambientais como integrantes de um universo maior.

Utiliza-se, na realização da pesquisa, o método hipotético-dedutivo, partindo da ideia de que é preciso desenvolver uma estratégia de educação ambiental que efetivamente promova mudanças de atitude e de valores éticos e morais, gerando, como consequência, mudanças de comportamento.

Este tema é especialmente importante em razão da necessidade de promover-se a proteção e preservação ambientais, sem descurar do desenvolvimento. Ademais, normas constitucionais e infraconstitucionais (como é o caso, por exemplo, da Lei n. 9.394, de 1996, e da Lei n. 9.795, de 1999) tornaram imperativo o processo de educação ambiental, de modo que a sociedade possa, com efetividade, participar das soluções para a construção de um meio ambiente que propicie, simultaneamente, desenvolvimento e qualidade de vida.

No segundo capítulo, abordar-se-á, ainda que de forma sucinta, algumas questões filosóficas. O objetivo será compreender a relação do homem com a natureza, envolvendo especialmente os fatores éticos e morais.

No capítulo três, o objeto de investigação volta-se para a educação ambiental propriamente dita, quando se buscará compreender a complexidade do processo educacional - que é observada também em outros países - e avaliar a melhor alternativa para que este processo torne-se efetivo, no sentido de provocar mudanças de atitudes e uma reconstrução de valores éticos e morais. 
Ao final, apresentam-se as considerações finais, procurando indicar o caminho a ser trilhado pelos educadores ambientais (e pelas políticas públicas relacionadas ao tema), no sentido de interpretarem a preservação do meio ambiente como integrante de um escopo mais amplo, que inclui os aspectos culturais, políticos e econômicos, todos essenciais para o desenvolvimento social na contemporaneidade.

\title{
2 Concepções filosóficas: a natureza e o homem
}

A correlação do homem contemporâneo com aquele delineado pelos filósofos da antiguidade é evidente, eis que o homem, como ser provido pela natureza, vem se transformando no decorrer dos séculos, desde a era primitiva até a atualidade.

No presente capítulo pretende-se abordar a questão da natureza humana sob o viés da razão, da ética e da moral e, nessa trilha, procurar compreender a relação desse "homem" com o meio ambiente. Destarte, inicia-se a reflexão a partir da seguinte lição:

\begin{abstract}
Inúmeras são as teorias a respeito da data e do modo de formação do planeta Terra e do aparecimento do homem. Entretanto, existe um consenso científico, pois desde os primórdios, existe uma relação entre os seres humanos e a natureza, sendo desta que aqueles retiram elementos essenciais para sobreviverem. [...] A espécie humana se multiplicou ao longo do globo terrestre. A necessidade da humanidade por alimentos, moradia, vestuário, trabalho, transporte, agricultura, industrialização e urbanização, subordinou a natureza, renegando-a a segundo plano, priorizando as demandas, imprescindíveis ou não (SILVA, 2012, p.59).
\end{abstract}

A filosofia clássica fundamenta-se na cultura grega dos séculos VIII e VII a.C., quando, já ali, se coloca em evidência dois traços bastante distintos: o homem como animal que fala e como animal político. É o que nos ensina Vaz (2006, p.20), aduzindo em seguida que tais características essenciais do homem "se manifestam em atividades dotadas de finalidades específicas, a atividade da contemplação (theoria ${ }^{l}$ ) e a atividade do agir moral e político $\left(\right.$ praxis $\left.^{2}\right)$." O moralismo prevalecente assenta-se na ideia da responsabilidade pessoal, em que o homem passa a compreender seu poder de decisão e, a partir dele, identificar méritos e deméritos.

[...] Convém assinalar a admiração (thauma) pela ordem e beleza que fazem do universo visível um todo bem adornado (kósmos). Dessa admiração, segundo o testemunho de Platão e Aristóteles, terá origem a filosofia e, com ela, um estilo de vida que o homem grego reivindicará como próprio seu: vida teorética (theoretikós bios). A outra característica está ligada à descoberta da homologia ou correspondência que deve reinar entre a ordem do universo (que será tematizada filosoficamente no conceito de "natureza" ou physis) e a ordem da cidade (polis) regida por leis justas. Essa será uma das fontes da idéia (sic) grega de uma ciência do agir humano (Ética), cuja

\footnotetext{
${ }^{1}$ Termo grego que significa contemplação, no sentido de um "olhar consciente".

${ }^{2}$ É a atividade humana em sociedade e na natureza.
} 
imensa significação para a formação da idéia (sic) ocidental do homem é bem conhecida (VAZ, 2008, p.21).

Em Sócrates há uma reflexão sobre o que é propriamente humano (e sobre as coisas humanas), introduzindo-se a ideia da personalidade moral, sobre a qual assentase o edifício da Ética (e também do Direito). A teleologia do bem como instrumento de acesso para a compreensão do mundo e do homem, a prevalência da faculdade intelectual e a valorização ética do indivíduo são os traços principais do pensamento socrático, conforme aduz Vaz (2008, p.28-29).

Após mencionar a divisão da ética normativa em teoria moral e ética prática, Jamieson (2010, p.125) ensina que a primeira ocupa-se de definir quais espécies de coisas e de atos são bons e quais as relações entre o certo e o bom. Já a ética prática volta-se à avaliação de "coisas particulares como boas e más e diversos atos ou práticas como certas ou erradas (sic)."

Aristóteles trouxe grandes contribuições para a compreensão do homem, podendo-se definir como traços de sua concepção antropológica a estrutura biopsíquica ou teoria da psyché $e^{3}$, segundo a qual o homem é um ser composto de psyqué e de sôma ${ }^{4}$; a afirmação de que o homem é um zoom logikón $n^{5}$, distinguindo-se dos demais seres da natureza em decorrência de sua racionalidade; o homem como ser ético-político; e, por fim, o homem como ser de paixão e de desejo. Após lecionar nesse sentido, Vaz (2008, p.35-39) afirma que a investigação de Aristóteles sobre a racionalidade apresenta três pontos cruciais: o ponto de vista da psyché, sua estrutura e suas funções; o ponto de vista do finalismo da razão, considerando-se a atividade intelectual conforme o fim visado; e o ponto de vista dos processos formais do conhecimento, enfatizando-se a capacidade da racionalidade na formulação do mundo.

Ao abordar as ideias epicuristas, Medeiros (2002, p.73-74) fala de sua concepção materialista de realidade. O mundo constituir-se-ia de átomos e sua origem estaria nas causas naturais; a natureza, por sua vez, seria um lugar aprazível e poético. Foi por volta de 200 d.C., porém, que veio à tona a ideia de que o Universo teria sido criado por Deus e que a natureza está a serviço do homem, que é, em verdade, o centro de todas as coisas.

Tratando da concepção humanista, própria da Renascença, Vaz (2008, p.69-70) destaca que as ideias dessa época representam uma ruptura e ao mesmo tempo uma transição. A imagem cristão-medieval do homem dá lugar à imagem racionalista, que dominará os séculos XVII e XVIII. Nesse sentido, leciona o autor que

O tema da dignidade do homem reaparece na Renascença [...]. No entanto, uma notável diferença de acento deve ser assinalada na celebração da dignidade do homem na literatura antiga e nos autores da Renascença. [...] No segundo caso, é o agir, o operari, a capacidade de transformação do seu mundo que passa a ser o indício incontestável

\footnotetext{
${ }^{3}$ Elemento intrínseco ao ser vivo, diferenciada entre homens e animais somente pela intensidade e profundidade em que ocorre com cada um deles. A alma ou psique compõe as faculdades de expressar as emoções humanas.

${ }^{4} \mathrm{O}$ corpo físico; a morada da alma (psyqué).

${ }^{5}$ Homem racional, finalista, que estabelece formas de conhecer.
} 
da superioridade do homem, anunciando-se aqui uma das direções fundamentais da antropologia moderna (VAZ, 2008, p.69).

É na Renascença que se observa uma profunda mudança de pensamento. O mundo da natureza, de acordo com Medeiros (2002, p.74), passa a ser visto não como um organismo inteligente, ativo e vivo, mas como uma manifestação divina e, um pouco mais tarde, como máquina. Trata-se de uma releitura das ideias de Aristóteles, todavia, dentro de uma concepção de ordem e regularidade.

O mundo não é mais a physis antiga dotada de um princípio imanente de movimento (arqué kinêseôs, na definição de Aristóteles), mas a grande máquina capaz de ser analisada pela razão e por ela reproduzida na forma de um modelo matemático. Uma consequência importante da antropologia racionalista é o progressivo atenuar-se da distinção entre "natural" e "artificial" (entre a physis e a téchne) que era um dos fundamentos da visão aristotélica do mundo (VAZ, 2008, p.74).

Nessa breve incursão pela filosofia, há que se trazer a visão contemporânea ora vigente. Segundo Medeiros (2002, p.79), a descoberta dos genes na metade do século XX trouxe um novo paradigma, simbolizado pelo reducionismo molecular, em que o termo "natureza" (agora denominado ambiente ou meio ambiente) é substituído pelo termo "vida". Nossa sociedade se "esquece" não apenas da natureza, mas também do homem e sua herança biológica e cósmica, podendo tal cenário ser o prelúdio da substituição da natureza e do próprio homem pela tecnologia. E complementa:

Em final do século XX, parece-nos que não dispomos de um único conceito de natureza, além das idéias (sic) ora antropocêntricas ora biocêntricas (de uma natureza intocada, inculta e selvagem). Nós nomeamos a natureza como "social, biológica, histórica e cultural" mas, apesar disso, ela conserva sua dinâmica de natureza; o homem não tem tanto controle sobre ela como tem de sua "própria sociedade" (MEDEIROS, 2002, p.80).

A relação do homem com a natureza - a partir de agora entendida como "ambiente" ou como "meio ambiente" - faz emergir questões éticas e morais, entendidas como balizadoras de uma conduta humana que pode levar-nos à compreensão do posicionamento do homem em face dos bens e recursos ambientais.

\subsection{A moral como sustentáculo do comportamento (ambiental) humano}

Após salientar que a ideia de moralidade, nos tempos atuais, está vinculada à obediência em relação às regras instituídas pelas autoridades, não importando quão teratológicas possam ser, Jamieson $(2010$, p.54) aduz que é imprescindível "retornar à fonte e examinar os conceitos e instituições da moralidade desde o alicerce." Tal investigação levará ao entendimento do porque de se pensar o meio ambiente sob o ponto de vista ético. Prossegue o autor, afirmando que 
[...] Moralidade é um sistema comportamental, com um certo tom apaziguador, que evoluiu entre determinados animais sociais com o propósito de regular suas interações. Tais sistemas são característicos de animais sociais vivendo sob certas condições, tais como escassez, porque, nessas circunstâncias, se cada um agir apenas por si e para si pode ocorrer um desastre para todo mundo. Isso foi absolutamente demonstrado por Thomas Hobbes, filósofo do século XVII, na descrição do que ele chamou de "o estado de natureza" (JAMIESON, 2010, p.54).

A moralidade, induvidosamente, está relacionada à capacidade humana de controlar seus impulsos e desejos, bem como de vivenciar sentimentos e percepções como empatia, simpatia, generosidade, solidariedade, assertividade. O "colocar-se no lugar do outro" é uma habilidade do homem - e somente dele - capaz de suprimir ou estimular determinados comportamentos morais.

O amoral, por sua vez, opta por abandonar todos os delineamentos da moralidade. "A moralidade nada tem a ver com o modo pelo qual ele vai viver sua vida. Ele vai agir como lhe agradar, sem se preocupar com o estado de natureza, regras morais ou coisas do tipo" (JAMIESON, 2010, p.60).

Ao discorrer sobre o consequencialismo, Santos (2012, p.420) aduz que não só as ações, mas também as omissões são levadas em conta na avaliação do comportamento moral ou amoral do homem. Tal análise considera as prováveis consequências das ações ou omissões (boas ou ruins, desejáveis ou indesejáveis) e se a ação (ou omissão) é moralmente obrigatória, permitida ou proibida. Entretanto, o autor faz o seguinte alerta:

O emprego do termo "consequências", ao lado de suas classificações como boas ou ruins, precisa ser considerado atentamente. Não se fará um julgamento adequado partindo meramente de tais qualificadores, como se, por si só, fossem suficientes para nos possibilitarem conclusões inequívocas. Nesse sentido, nem toda ação que produz boas consequências é já, por isso, um mandamento moral, assim como nem toda ação com consequências ruins, em toda e qualquer circunstância, é moralmente proibida (SANTOS, 2012, p.421).

O consequencialismo - que atingiu seu ápice nos séculos XVIII e XIX - sustenta que as ações são moralmente certas, erradas ou indiferentes, unicamente em razão de suas consequências. Desse modo, de acordo com essa teoria, ao decidir o que fazer, o homem deve considerar as consequências de sua ação em relação a todos que forem potencial ou efetivamente afetados.

Todavia, o consequencialismo, sob o viés utilitarista, pode conduzir o estudioso a um cenário bastante controverso. É o que nos explica Jamieson (2010, p.138):

Os eticistas ambientais, tipicamente, têm observado o consequencialismo com desconfiança. Isso pode ter relação com o fato de que a versão mais proeminente do consequencialismo é o utilitarismo, e o utilitarismo inspira grande hostilidade entre os 
filósofos de modo geral. O utilitarismo é quase sempre pensado como uma concepção grosseira que preza a "utilidade" sobre outros valores mais importantes e sustenta que "os fins justificam os meios".

Segundo Geraldo (2014, p.2), o utilitarismo insere-se adequadamente no rol das teorias consequencialistas, uma vez que, em cada caso concreto, deve-se avaliar os efeitos provocados pelas ações e, a partir daí, refletir se a conduta é (eticamente) reprovável, a partir do critério da utilidade. Traz o autor interessante posicionamento:

Preconiza, então, que as ações humanas devem seguir o princípio da utilidade, consistente na consideração da quantidade de prazer e dor que as ações provocam aos indivíduos. As ações devem considerar todos os interesses de maneira que nenhum contrainteresse deva ser desconsiderado, ou tenha preponderância sobre o outro. Além disto, o número de pessoas atingidas pelas ações são objetos de análise. Busca-se sempre promover a maior quantidade de prazer possível ao maior número de indivíduos, ao passo que se evita o desprazer numa proporção inversa. É curioso notar que há um paralelismo entre o prazer e o sofrimento para o inglês de tal modo que a maximização de um significa proporcionalmente a minimização de outro (GERALDO, 2014, p.2).

A teoria utilitarista (consequencialista) deve ser considerada no relacionamento atual entre o homem e o meio ambiente. Apesar de perquirir-se acerca das consequências de suas ações (boas, ruins ou indiferentes), o ser humano tem feito uso dos recursos ambientais levando em conta sua utilidade (a lógica de que "o fim justificam os meios").

Já se reconhecem, porém, os efeitos que o uso desmedido do meio ambiente tem provocado na humanidade e no planeta Terra.

Os observadores argutos têm visualizado esse novo limite no horizonte, mas até pouco tempo atrás ele não havia atingido as pessoas. Ele só foi batizado há menos de três décadas: o limite da "capacidade de renovação" de ecossistemas, ou do "meio ambiente" do planeta Terra. Este limite está sendo reconhecido como uma crise ambiental global. Os recursos são objetivamente limitados por causa das limitações do planeta (HELLER, 1999, p.113).

Realça-se, no momento histórico atual, a importância da participação do indivíduo nos processos sociais, econômicos e ambientais, com vistas a equilibrar os diversos valores que hoje interferem no bem estar da humanidade. Nesse contexto, destaca Heller (1999, p.115) que essa participação não é apenas formal, mas substancial, salientando que aqueles que participam do "jogo democrático" estão equipados com duas vigorosas ferramentas: sua integridade pessoal e seus direitos formais, consubstanciados nos direitos humanos de segunda e terceira geração.

Para reverter o quadro caótico ambiental, é imprescindível que a sociedade cumpra seu papel regulador, em busca do equacionamento dos interesses econômicos e ambientais. Essa participação ativa, contudo, condiciona-se a três elementos 
umbilicalmente vinculados: a informação, a educação e a participação propriamente dita. Nesse espeque, a educação ambiental assume um papel relevante: é o homem, com sua racionalidade, buscando compreender o mundo que o cerca para, a partir daí, participar ativamente do processo de (re)construção de novos paradigmas, que garantam a sua sobrevivência enquanto espécie e uma adequada qualidade de vida.

\section{Educação ambiental: transformando paradigmas}

Para a abordagem da questão relacionada à educação ambiental far-se-á incursões pelos princípios constitucionais (e infraconstitucionais) vigentes e pelo viés do processo educacional lato sensu.

A Constituição da República de 1988 dedicou atenção especial ao meio ambiente. Dentre os vários dispositivos pertinentes ao tema ${ }^{6}$, o art. 225 merece notável destaque. Já no caput estabelece que o Poder Público e a coletividade têm o dever de preservar e defender o bem ambiental. Desse modo, a obrigação pela proteção e preservação do meio ambiente não é atribuída apenas ao Estado, mas também à sociedade.

No que toca à educação ambiental, o $\S 1^{\circ}$, inciso VI, do mesmo art. 225, estabelece que ao Poder Público incumbe "promover a educação ambiental em todos os níveis de ensino e a conscientização pública para a preservação do meio ambiente".

Tratando-se da educação ambiental, esta é imprescindível para estabelecer e nortear uma política ambiental, daí por que, depois de preconizada no art. $2^{\circ}$ da Lei $6.938 / 81$, foi recepcionada no art. 225 , $\S 1^{\circ}, \mathrm{VI}$, da CF, com incentivo da promoção desse tipo de educação em todos os níveis de ensino (LANFREDI, 2007, p.138).

Aduz Cureau e Leuzinger (2013, p.55) que "o princípio da informação engloba a obrigação do Estado de oferecer educação ambiental". Não obstante pensarmos de modo diverso, no sentido de que a educação é a obrigação maior, da qual a informação (e também a participação) é corolário, salienta-se o posicionamento da autora no sentido de que somente com a conscientização provocada pela educação e pela informação seria possível formar-se uma "sociedade ciente da importância de proteger o ambiente natural, capaz, assim, de cumprir a obrigação constitucional de protegê-lo e preservá-lo para as presentes e para as futuras gerações."

Também Álvares e Vega (2009, p.248) lecionam que os indivíduos somente aderem a condutas ambientalmente responsáveis se estiverem suficientemente informados sobre os problemas ambientais e se estiverem motivados por tais problemas. É importante, segundo os autores, que os indivíduos vejam-se como capazes de gerar mudanças qualitativas e estejam convencidos da efetividade de suas ações. ${ }^{7}$

${ }^{6}$ Cf. art. $5^{\circ}$, caput (direito à vida); art. $5^{\circ}$, XXIII (função social da propriedade); art. $7^{\circ}$, XXII (meio ambiente do trabalho); art. 21, XIX, XX e XXIII; art. 23, VI e VII; art. 24, VI, VII e VIII; art. 170, III e VI; dentre outros.

7 Texto original: "En todos ellos se plantea que los individuos sólo realizan conductas ambientalmente responsables cuando están suficientemente informados sobre la problemática ambiental, se encuentran 
É cediço, entretanto, que o meio ambiente (por sua complexidade) exige uma abordagem multidisciplinar, impondo ao processo educativo uma visão mais abrangente, eis que deve abarcar não somente as questões ambientais, mas também econômicas, de soberania nacional, histórico-culturais e sociais. É por este motivo que Jacobi (2003, p.196) aduz que o enfoque da educação ambiental deve assumir uma perspectiva holística, tendo como desafio "formular uma educação ambiental que seja crítica e inovadora, em dois níveis: formal e não formal." Também Machado (2014, p.174), ao fazer referência à Lei n. 9.795/1999 (que instituiu a Política Nacional de Educação Ambiental - PNEA), leciona que é preciso considerar, sob o enfoque da sustentabilidade, a concepção de meio ambiente de modo total, levando em conta a interdependência entre o meio natural, o socioeconômico e o cultural.

Comentando especificamente sobre a PNEA, Sorrentino e Trajber (2005, p.287), ensina que "a abordagem do Programa Nacional de Educação Ambiental reitera um entendimento, historicamente construído, dos desafios desta como processo dialético de transformação social e cultural."

A educação ambiental é essencial - pressuposto basilar - à efetiva participação da sociedade "no controle do Estado e da iniciativa privada com vistas à preservação do meio ambiente" (SILVA, 2014, p.81). Desse modo, e não por outro motivo, um dos objetivos primordiais da educação ambiental é a efetiva participação do indivíduo e da coletividade na preservação do equilíbrio do meio ambiente.

A atuação dos indivíduos em situações ambientais conflitivas e problemáticas é a finalidade principal do processo de sensibilização. Após firmar tal entendimento, Benegas e Márcen (1995, p.12) ensinam que as propostas para a educação ambiental devem garantir uma educação moral que ajude o indivíduo a conviver em uma sociedade democrática e pluralista. Porém, como não há um modelo a ser seguido, há que se construir uma moral autônoma. ${ }^{8}$

A educação - de modo geral - é um dos principais instrumentos na conformação da personalidade e, nesse contexto, é preciso que o processo educacional considere todas as nuances da vida em sociedade, o que abrange os aspectos éticos, econômicos, culturais e sociais. Corroborando essa afirmativa, Lanfredi (2007, p.142-143) ensina:

\footnotetext{
O que se observa é que esse tipo de educação se apresenta como uma nova forma de ver o papel do ser humano no mundo, propondo modelos de relacionamentos mais harmônicos com a natureza e novos valores éticos. [...] pode-se dizer, entre outras várias maneiras de conceituar a educação ambiental que ela "é aprendizagem de como gerenciar e melhorar as relações entre a sociedade humana e o ambiente, de modo integrado e sustentável."
}

Essa nova visão da educação - cerne da educação ambiental - leva em conta componente da mais alta relevância, que é o da inevitável interdisciplinariedade, consistindo na "busca de uma concepção do mundo que supera a informação

motivados hacia ella y, además, se ven capaces de generar cambios cualitativos, están convencidos de la efectividad de su acción y de que ésta no les generará dificultades importantes."

${ }^{8}$ Texto original: "Actuar ante una situación ambiental que es conflictiva y problemática es el fin último de un largo proceso de sensibilización ambiental. Además, proponer situaciones de aprendizaje para la E.A. tiene una finalidad principal que es ofrecer puntos de referencia para poder garantizar una educación moral que nos ayude a convivir en una sociedad democrática y pluralista. [...] No existe un modelo a repetir. Así pues, se trata de ir construyendo una moral autónoma." 
compartimentada, fragmentada e dissociada da existência social e natural do Planeta" (LANFREDI, 2007, p.147).

Ressaltando que a educação ambiental tem como viés construir uma cultura ecológica que passe a entender "natureza" e "sociedade" como elementos intrinsecamente relacionados e que não podem ser pensados isoladamente, Sorrentino e Trajber (2005, p.288-289) discorrem que

\begin{abstract}
A educação ambiental nasce como um processo educativo que conduz a um saber ambiental materializado nos valores éticos e nas regras políticas de convívio social e de mercado, que implica a questão distributiva entre benefícios e prejuízos da apropriação e do uso da natureza. Ela deve, portanto, ser direcionada para a cidadania ativa considerando seu sentido de pertencimento e co-responsabilidade ( que, por meio da ação coletiva e organizada, busca a compreensão e a superação das causas estruturais e conjunturais dos problemas ambientais. (grifos nossos)
\end{abstract}

Segundo Sauvé (2005, p.317-319), o educador deve levar em consideração as facetas que circundam o tema do meio ambiente, de modo que a intervenção educacional seja a mais adequada. Tais facetas abarcam o meio ambiente como natureza (para apreciação e preservação), o meio ambiente como recurso (envolvendo a questão do consumo responsável e da repartição equitativa), o meio ambiente como problema (volta-se para a questão de compreender os problemas ambientais próprios da sociedade contemporânea), o meio ambiente como sistema (no sentido da interseção das questões ambientais com outras que se apresentam na vida social), o meio ambiente como lugar (o ambiente da vida cotidiana, onde o indivíduo vive e se relaciona), o meio ambiente como biosfera (considerando as realidades socioambientais em nível global) e, por fim, o meio ambiente como projeto comunitário (lugar em que se desenrolam as mudanças desejadas no seio da coletividade). Complementa o autor:

A educação ambiental não é, portanto, uma "forma" de educação (uma
"educação para...") entre inúmeras outras; não é simplesmente uma
"ferramenta" para a resolução de problemas ou de gestão do meio
ambiente. Trata-se de uma dimensão essencial da educação
fundamental que diz respeito a uma esfera de interações que está na
base do desenvolvimento pessoal e social: a da relação com o meio em
que vivemos, com essa "casa de vida" compartilhada. A educação
ambiental visa a induzir dinâmicas sociais, de início na comunidade
local e, posteriormente, em redes mais amplas de solidariedade,
promovendo a abordagem colaborativa e crítica das realidades
socioambientais e uma compreensão autônoma e criativa dos
problemas que se apresentam e das soluções possíveis para eles
(SAUVÉ, 2005, p.317).

Conforme se observa, a educação - e sobretudo a educação ambiental - tem como escopo construir (ou despertar) nos indivíduos valores éticos e morais, que o façam compreender a dinâmica socioambiental de modo a sopesar os benefícios e os prejuízos da exploração e consumo dos recursos naturais. Tal compreensão nada mais é 
do que depreender as consequências de sua ação (boas ou ruins), à semelhança do que preconiza a teoria consequencialista estudada alhures.

\subsection{Concepções brasileiras de educação ambiental}

Em face dos direcionamentos constitucionais e infraconstitucionais, não há que se questionar a imprescindibilidade da educação ambiental como meio de disseminar conhecimento, informação e novos comportamentos em face do meio ambiente.

Entretanto, o processo educacional ambiental perpassa pela instituição de (novas) políticas públicas:

O grande desafio que se coloca é formular políticas públicas que estimulem e promovam essa nova forma de relacionamento com o consumo e que controlem as práticas predatórias e insustentáveis. [...] O poder público, em todos os níveis, deve priorizar a formulação de políticas públicas integradas que adotem tecnologias limpas, promovam campanhas de conscientização sobre os fatores que provocam a insustentabilidade ambiental e realizem a efetiva implementação de políticas socioambientais urbanas, com ênfase no consumo sustentável, na coleta seletiva, na reciclagem e na redução do desperdício nas atividades públicas e privadas (JACOBI, 2012, p.30).

Apesar da Constituição da República de 1988 já ter completado mais de vinte e cinco anos e a Lei que instituiu a Política Nacional de Educação Ambiental (Lei n. 9.795/1999) ter sido promulgada há praticamente quinze anos, nota-se que a legislação educacional brasileira ainda trata a educação ambiental de maneira superficial. A Lei de Diretrizes e Bases da educação (Lei n. 9.394/96) faz referência às questões ambientais apenas no art. 32 , inciso II e no art. $36, \S 1^{\circ}$.

Apesar disso, Sorrentino e Trajber (2007, p.30) entendem que os princípios e objetivos delineados na Política Nacional de Educação Ambiental, permitem que se extraiam algumas diretrizes comuns, "como a visão da complexidade da questão ambiental, as interações entre ambiente, cultura e sociedade, o caráter crítico, político, interdisciplinar, contínuo e permanente."

Talvez essa intrincada relação - em que a educação ambiental abarca uma série de outros elementos sociais - seja a causa das dificuldades em se encontrar um modelo educacional que efetivamente cumpra o seu papel de educar, envolvendo no processo os diversos atores sociais. Nesse sentido:

A análise da gestão da educação ambiental revela uma realidade preocupante e contraditória com os princípios gerais e participativos da educação ambiental proclamados e consensuados (sic) em todos os documentos nacionais e internacionais disponíveis e divulgados nos últimos 30 anos. Com efeito, seja na promoção de uma iniciativa, no envolvimento dos atores que participam do processo ou na percepção da importância da contribuição dos diversos atores e saberes na compreensão do ambiente, tem-se que as escolas demonstraram um processo contraditório e de distanciamento da comunidade (LOUREIRO; COSSIO, 2007, p.61). 
As estratégias de educação ambiental no Brasil, na grande maioria das vezes, restringem-se a práticas das mais comezinhas. É comum verificarmos nas escolas programas que incentivam e promovem, por exemplo, o plantio de árvores, a limpeza de praças, praias e áreas de preservação, a disseminação da importância da preservação de espécies animais em extinção, etc.

Não obstante louváveis, essas práticas estão muito longe de representarem a educação ambiental propriamente dita. Loureiro (2007, p.67) explica que uma tendência ainda presente nos dias atuais é a ideia de que a educação ambiental resume-se à "transmissão de condutas ecologicamente corretas e a sensibilização individual para a beleza da natureza, levando-nos a mudar de comportamento". O autor explica, contudo, que essa visão ignora os processos de aprendizagem e a "necessidade social de se mudar atitudes, habilidades e valores e não apenas comportamentos."

É preciso que a educação ambiental seja transformadora do indivíduo e da sociedade, reformulando conceitos éticos e morais, atitudes, valores e, por consequência, comportamentos. É imperioso reconstruir uma nova relação entre o homem e a natureza, de modo que aquele se veja nesta, reconhecendo-se como integrante de um sistema interdependente, em que a preservação de cada elemento é a garantia da própria sobrevivência da raça humana.

\subsection{Concepções espanholas de educação ambiental}

O problema da educação ambiental não aflige apenas o Brasil. Países com grau elevado de desenvolvimento vivenciam situações das mais intrincadas, fazendo com que estudiosos se aprofundem na questão da preservação do meio ambiente e do processo educativo (ambiental).

Inicia-se a presente seção com a afirmação de Benegas e Marcén (1995, p.13) de que o sistema de valores do indivíduo tem relação estrita com a forma como ele se relaciona com a natureza e com os demais. O desenvolvimento desses valores é um processo social, no sentido de que as influências sociais vão moldando tais valores até que se consolidem, podendo, ainda assim, ser modificados em razão de novas crenças e doutrinas. $^{9}$

Esse posicionamento nos leva à conclusão - talvez óbvia - de que o indivíduo é fruto de suas relações sociais. A interação social molda a personalidade, as crenças e os valores individuais. Daí a importância da educação ambiental, no sentido de inserir esse elemento (meio ambiente) dentre os valores e crenças do educando.

Para Álvares e Vega (2009, p.246), a educação ambiental não deve abranger apenas o meio ambiente propriamente dito, mas deve levar os indivíduos a interpretar, compreender e conhecer a complexidade e globalidade dos problemas que se produzem no mundo e ensinar atitudes, valores e comportamentos que fomentem uma vida

\footnotetext{
${ }^{9}$ Texto original: "En efecto, el sistema de valores tiene mucho que ver con la manera como se ve el individuo, el papel que ocupa en relación com la naturaleza y con los demás. El desarrollo de los valores es principalmente un proceso social y se va forjando progresivamente en las personas. De hecho, las influencias sociales van moldeando el sistema de valores hasta que éste se consolida y aún así se modifica según nuevas modas, creencias, doctrinas, etc.”|
} 
sustentável, a partir de uma nova visão econômica, social, política e cultural, levando a humanidade a um modelo de desenvolvimento que promova não só a melhora ambiental, mas também social, econômica e política. ${ }^{10}$

Trata-se, como se vê, de compreender o desafio ambiental sob o viés interdisciplinar, no qual há uma inevitável interseção da questão do meio ambiente com as questões sociais, políticas e culturais.

Nesse sentido, Marcote e Suárez (2005, p.4) alertam que a educação ambiental deve, necessariamente, abandonar o pensamento único, promovendo a construção do conhecimento balizada por uma visão sistêmica e completa do funcionamento do mundo e formando pessoas vocacionadas a pensar alternativas para os problemas ambientais. $^{11}$

Os mesmos autores concluem que a ideia de educação ambiental não deve ser reduzida aos processos de educar para a conservação da natureza ou para a mudança de comportamentos. Mais do que isso, a educação ambiental deve promover a mudança da sociedade em busca de uma consciência orientada para o desenvolvimento humano que seja, ao mesmo tempo, causa e efeito da sustentabilidade e da responsabilidade global. ${ }^{12}$

\section{Considerações finais}

A relação do homem com a natureza e com o ambiente que o cerca sofreu modificações conceituais desde os primórdios até os dias atuais. O ser humano já foi visto como parte integrante do ecossistema, como também já foi concebido como elemento que deve dominar a natureza, colocando-a a seu serviço.

$\mathrm{Na}$ contemporaneidade, entretanto, os problemas ambientais exsurgem como algo que deve ser estudado e solucionado, haja vista que colocam em risco a própria sobrevivência da humanidade.

Nesse aspecto, a educação ambiental deve exercer papel primordial, como instrumento de promoção da mudança de atitudes, de conceitos éticos e morais, de valores e, por fim, de comportamentos.

Não por outro motivo, a educação ambiental recebeu ampla regulamentação legal. Prevista na Constituição da República de 1988, art. 225, §1 ${ }^{\circ}$, inciso VI, foi também objeto de tratamento na Lei n. 6.938/1981, art. $2^{\circ}$, Lei n. 9.394/1996 (Lei de

\footnotetext{
${ }^{10}$ Texto original: "Es decir, ha de ser una educación 'para cambiar la sociedad'; una educación que ayude a los individuos a interpretar, comprender y conocer la complejidad y globabilidad de los problemas que se producen en el mundo y enseñe actitudes, conocimientos, valores, comportamientos, etc. que fomenten una forma de vida sostenible, de forma que se procuren los cambios económicos, sociales, políticos y culturales que nos lleven a alcanzar un modelo de desarrollo que implique no sólo una mejora ambiental, sino también una mejora social, económica y política a nivel global."

${ }^{11}$ Texto original: "Se trata de favorecer una construcción del conocimiento que abandone la consecución del pensamiento único y se encamine hacia una visión sistémica y compleja del funcionamiento del mundo y tender a lo que empieza a conocerse como educación global para formar personas que sean capaces de dar alternativas a la problemática ambiental."

12 Texto original: "Expresa, por tanto, la idea de una EA que no se reduce a educar para 'conservar la Naturaleza', 'concienciar personas' o 'cambiar conductas'. Su tarea es más profunda y comprometida: educar para cambiar la sociedad, procurando que la toma de conciencia se oriente hacia un desarrollo humano que sea simultáneamente causa y efecto de la sustentabilidad y la responsabilidad global."
} 
Diretrizes e Bases da Educação) e, de modo mais amplo e específico na Lei $\mathrm{n}$. 9.795/1999 (Política Nacional de Educação Ambiental).

Apesar disso, especialistas no assunto já observaram que muitas das práticas "educacionais" (ambientais) restringem-se a ações isoladas e desconectadas, que tendem a alterar comportamentos momentaneamente sem, contudo, promover a mudança de atitudes e valores pessoais e sociais.

O meio ambiente (e sua preservação) não pode ser visto como elemento isolado e dissociado de outros elementos da sociedade, como política, cultura e economia. Para que se dê um tratamento adequado à questão ambiental é preciso reconhecê-la como integrante de um sistema, no qual estão presentes outros elementos e valores sociais.

O processo de educação ambiental é, portanto, complexo, não se esgotando em práticas que, apesar de louváveis, estão longe de conduzirem o indivíduo a uma mudança efetiva de atitude.

O que se nota é que, apesar de uma ampla legislação a respeito de educação ambiental, o Brasil ainda procura dar os primeiros passos em direção a essa educação transformadora, que reformule atitudes e valores, de modo a alcançar uma amplitude que propicie a percepção do meio ambiente como componente de uma intrincada relação de vários elementos (ambientais, culturais, políticos e econômicos).

A situação encontrada em outros países, como Espanha, é bastante similar ao que se observa no Brasil. Há, do mesmo modo que aqui, uma preocupação em colocar a educação ambiental no bojo de um processo sistêmico, em que as questões ambientais sejam analisadas e solucionadas levando-se em conta os demais aspectos da vida social.

É preciso avançar. A educação ambiental não pode permanecer restrita a ações isoladas, como o plantio de árvores, a limpeza de praças, parques e áreas de preservação, a recolha de lixo nas praias, o incentivo para que torneiras sejam fechadas e lâmpadas sejam apagadas.

A educação ambiental, para que se torne efetiva, não pode se pautar em meras ações mas, diferentemente, deve promover a mudança de atitudes e de valores pessoais, éticos e morais, do indivíduo e da sociedade, em relação ao meio ambiente, de modo que o homem se veja parte integrante de um sistema que inevitavelmente incorpora, além dos aspectos ambientais, também as nuances da cultura, da política e da economia. É essa percepção sistêmica que propiciará mudanças consistentes de atitudes, viabilizando o denominado desenvolvimento sustentável e a sobrevivência da espécie humana.

\section{Referências}

ÁLVARES, Pedro; VEGA, Pedro. Actitudes ambientales y conductas sostenibles: implicaciones para la educación ambiental. Revista de Psicodidáctica. Madri: Universidad del País Vasco, v.14, n.2, p.245-260, 2009.

BENEGAS, Javier; MARCÉN, Carmelo. La educación ambiental como desencadenante del cambio de actitudes ambientales. Revista Complutense de Educación. Madrid: Universidad Complutense, v.6, n.2, p.11-28, 1995.

CUREAU, Sandra; LEUZINGER, Marcia Dieguez. Direito ambiental. Rio de Janeiro: Elsevier, 2013. 
GERALDO, Pedro Heitor Barros. O utilitarismo e suas críticas: uma breve revisão. Disponível em: <http://docplayer.com.br/265473-O-utilitarismo-e-suas-criticas-umabreve-revisao.html>. Acesso em: 12 out. 2014.

HELLER, Agnes. A crise dos paradigmas em ciências sociais e os desafios para o século XXI. Rio de Janeiro: Contraponto, 1999.

JACOBI, Pedro Roberto. Consumo e sustentabilidade: educação, corresponsabilização e políticas públicas. Reflexão e práticas em educação ambiental. São Paulo: Oficina de Textos, p.29-31, 2012.

JACOBI, Pedro Roberto. Educação ambiental, cidadania e sustentabilidade. Cadernos de Pesquisa. São Paulo: USP, n.118, p.189-205, 2003.

JAMIESON, Dale. Ética e meio ambiente: uma introdução. São Paulo: SENAC-SP, 2010.

LANFREDI, Geraldo Ferreira. Política ambiental: busca de efetividade de seus instrumentos. 2.ed. rev., atual. e ampl. São Paulo: RT, 2007.

LOUREIRO, Carlos Frederico B. Educação ambiental crítica: contribuições e desafios. Vamos cuidar do Brasil: conceitos e práticas em educação ambiental na escola. Brasília: Ministério da Educação, p.65-71, 2007.

LOUREIRO, Carlos Frederico B.; COSSIO, Maurício F. Blanco. Um olhar sobre a educação ambiental nas escolas: considerações iniciais sobre os resultados do projeto "O que fazem as escolas que dizem que fazem educação ambiental?". Vamos cuidar do Brasil: conceitos e práticas em educação ambiental na escola. Brasília: Ministério da Educação, p.57-63, 2007.

MACHADO, Paulo Affonso Leme. Direito ambiental brasileiro. 22.ed. rev., ampl. e atual. São Paulo: Malheiros, 2014.

MARCOTE, P. Vega; SUÁREZ, P. Álvarez. Planteamiento de un marco teórico de la educación ambiental para un desarrollo sostenible. Revista Electrónica de Enseñanza de las Ciencias. Madrid: Universidad de Granada, v.4, n.1, 2005.

MEDEIROS, Mara Glacenir Lemes de. Natureza e naturezas na construção humana: construindo saberes das relações naturais e sociais. Ciência \& Educação. Baurú: Universidade Estadual Paulista "Júlio de Mesquita Filho", v.8, n.1, p.71-82, 2002.

SANTOS, Robinson dos. Responsabilidade e consequencialismo na ética de Hans Jonas. Revista de Filosofia Aurora. Curitiba: PUC Paraná, v.24, n.35, p.417-433, 2012.

SAUVÉ, Lucie. Educação ambiental: possibilidades e limitações. Educação e Pesquisa. São Paulo: USP, v.31, n.2, p.317-322, 2005.

SILVA, Rodrigo Zouain da. Os desafios do direito ambiental no limiar do século XXI diante da ineficácia do sistema jurídico ambiental brasileiro. Veredas do Direito. Belo Horizonte: ESDHC, v.9, n.18, p.57-87, 2012.

SILVA, Romeu Faria Thomé da. Manual de direito ambiental. 4.ed. rev., ampl. e atual. Salvador: JusPodivm, 2014.

SORRENTINO, Marcos; TRAJBER, Rachel. Políticas de educação ambiental do órgão gestor. Vamos cuidar do Brasil: conceitos e práticas em educação ambiental na escola. Brasília: Ministério da Educação, p.23-52, 2007.

SORRENTINO, Marcos; TRAJBER, Rachel; MENDONÇA, Patrícia; FERRARO JUNIOR, Luiz Antonio. Educação ambiental como política pública. Educação e Pesquisa. São Paulo: USP, v.31, n.2, p.285-299, 2005.

VAZ, Henrique C. de Lima. Antropologia filosófica. 8.ed. São Paulo: Loyola, 2006. 